\title{
Gambaran Medication Error Tahap Peresepan (Prescribing) di Apotek dan Klinik Keluarga Sehat Muncul Periode Januari - Desember Tahun 2020
}

\author{
Aulia Nadya Rizki Imansari ${ }^{1 *}$, Yuni Mutmainah ${ }^{1}$, Frida Kasumawati ${ }^{2}$ \\ ${ }^{1}$ DIII Farmasi, STIKes Widya Dharma Husada Tangerang \\ ${ }^{2} \mathrm{~S} 1$ Kesehatan Masyarakat, STIKes Widya Dharma Husada Tangerang \\ Email: aulia@masda.ac.id, yunimutmainah18@gmail.com fridaalfath@gmail.com
}

\author{
Korespondensi: \\ Aulia Nadya Rizki Imansari \\ DIII Farmasi, STIKes Widya Dharma Husada Tangerang \\ aulia@masda.ac.id
}

\begin{abstract}
Abstrak
Medication error adalah suatu kejadian yang tidak hanya merugikan pasien tetapi juga dapat membahayakan keselamatan pasien yang dilakukan oleh petugas kesehatan khususnya dalam hal pelayanan pengobatan pasien. Medication error dapat terjadi di dalam tiap proses pengobatan, salah satunya pada fase prescribing. Adanya medication error fase prescribing apabila komponen seperti kelengkapan data pasien, data dokter, dan tanggal resep belum belum lengkap $100 \%$ pada lembar resep. ${ }^{3}$ Tujuan penelitian ini adalah untuk mengetahui persentase kejadian medication error pada tahap prescribing dalam pelayanan pengobatan di Apotek dan Klinik Keluarga Sehat Muncul. Penelitian ini merupakan penelitian deskriptif secara retrospektif. Pengumpulan data menggunakan metode teknik non probability sampling dengan jumlah pengambilan sempel resep sebanyak 270 resep pada bulan Januari - Desember 2020 di Apotek dan Klinik Keluarga Sehat Muncul. Dari hasil penelitian menunjukkan potensi kejadian medication error pada kelengkapan administratif yaitu meliputi berat badan $100 \%$, jenis kelamin $87 \%$, paraf dokter $83 \%$, umur pasien $60 \%$, SIP dokter $57 \%$, tanggal resep $27 \%$, nama dokter $24 \%$, dan nama pasien $1 \%$. Sedangkan pada kelengkapan farmasetik potensi kejadian medication error yaitu meliputi ketidaklengkapan kekuatan sediaan $77 \%$, bentuk sediaan $28 \%$. Masih ditemukan ketidaklengkapan pada penulisan resep yang berpotensi terjadi nya medication error di apotek dan klinik keluarga sehat muncul. Hasil penelitian ini diharapkan dapat membantu meningkatkan kualitas pelayanan kepada pasien dan mencegah terjadinya medication error pada fase prescribing.
\end{abstract}

Kata Kunci: medication error; fase prescribing; Apotek 


\title{
DESCRIPTION OF MEDICATION ERROR IN THE PRESCRIPTION STAGE IN HEALTHY FAMILY PHARMACEUTICAL AND CLINIC APPEARS THE PERIOD OF JANUARY-DECEMBER 2020
}

\begin{abstract}
Medication error is an event that can harm the patient so that it can endanger patient safety by health workers, especially in terms of patient treatment services. Medication errors can occur in every treatment process, one of which is in the prescribing phase. The occurrence of medication errors in the prescribing phase if the components such as the completeness of patient data, doctor data, and the date of the prescription are not completely $100 \%$ complete on the prescription sheet. treatment in pharmacies and healthy family clinics appeared. This study is a retrospective descriptive study. The data collection used a non-probability sampling technique with a total of 270 prescription samples taken from January to December 2020 at pharmacies and healthy family clinics. The results of the study indicate the potential incidence of medication errors in administrative completeness, including body weight $100 \%$, gender $87 \%$, doctor initials $83 \%$, patient age $60 \%$, doctor SIP 57\%, prescription date $27 \%$, doctor name $24 \%$, and name $1 \%$ patients. Meanwhile, in pharmaceutical completeness, the potential incidence of medication errors includes incomplete strength of $77 \%$ of dosage forms, $28 \%$ of dosage forms. Incomplete prescriptions are still found in the writing of prescriptions that have the potential for medication errors to appear in pharmacies and healthy family clinics. The results of this study are expected to help improve the quality of service to patients and prevent medication errors in the prescribing phase.
\end{abstract}

Keyword: medication error, fase prescribing, Apotek

Received: 30 September 2021

Accepted: 21 Desember 2021

\section{PENDAHULUAN}

Kesalahan pengobatan (medication error) yang dapat disingkat dengan ME merupakan permasalahan yang masih terjadi dalam bidang kesehatan yang dapat menimbulkan dampak bagi seorang pasien mulai dari risiko ringan hingga risiko kematian pada pasien $^{1,2}$. Standar pelayanan kefarmasian di apotek menjelaskan bahwa upaya pencegahan terjadinya medication error sebenarnya dapat dilakukan dengan melakukan kegiatan monitoring penggunaan obat, evaluasi dan mendokumen tasikan segala aktivitas pelayanan pengobatan pada pasien ${ }^{3,4}$. Sebagaimana monitoring penggunaan obat berguna untuk mengetahui tujuan akhir dari pengobatan pasien ${ }^{5,6}$.

Hasil data yang diperoleh dari apotek dan klinik keluarga sehat muncul bahwa selama tahun 2020 jumlah resep yang masuk ke apotek dan klinik keluarga sehat muncul 
mencapai 500 hingga 800 resep. Banyaknya resep yang masuk di apotek dan klinik keluarga sehat muncul dapat berpotensi untuk terjadinya medication error, mengingat selama ini belum pernah dilakukan evaluasi pada setiap resep yang ada di apotek dan klinik keluarga sehat muncul. Tujuan penelitian ini adalah untuk mengetahui prescribing error yang sering terjadi pada lembar resep di apotek dan klinik keluarga sehat muncul yang meliputi kajian administratif dan kajian farmasetik yang tidak lengkap.

\section{METODE PENELITIAN}

\section{Alat dan Bahan}

Populasi penelitian ini adalah semua resep yang ada di Apotek dan Klinik Keluarga Sehat Muncul dengan jumlah lembar resep sebanyak 840 pada periode Januari - Desember 2020. Sampel yang digunakan adalah resep pasien yang ada di Apotek dan Klinik Keluarga Sehat Muncul sebanyak 270 resep. Pengambilan jumlah sampel dengan mengikuti teknik sampling. Adapun teknik pengambilan sampel, dengan menggunakan teknik non probability sampling yaitu systematic sampling. Teknik sampling yang digunakan dengan cara jumlah sampel yang diperoleh dari perhitungan rumus Slovin kemudian dibagi menjadi 12 bulan (Januari-Desember) 270:12 = 22,5 resep/bulan, sehingga untuk tiap bulannya dapat mengambil 22 resep atau 23 resep untuk mendapatkan 270 lembar resep dalam setahun.

\section{Rancangan Penelitian}

Penelitian ini merupakan jenis penelitian deskriptif, dengan desain penelitian yang digunakan adalah cross sectional, penelitian cross sectional merupakan rancangan penelitian dengan melakukan pengukuran atau pengamatan hanya sekali waktu, mungkin periode harian, mingguan, atau bulanan ${ }^{7}$. Kemudian untuk pengambilan data dalam penelitian ini yaitu data sekunder berupa data resep yang bersifat retrospektif.

\section{HASIL DAN PEMBAHASAN}

Pada penelitian ini, sebanyak 270 lembar resep diamati sesuai dengan kelengkapan administratif yang meliputi nama pasien, umur pasien, jenis kelamin pasien, berat badan pasien, nama dokter, SIP dokter, paraf dokter, tanggal penulisan resep, sedangkan kelengkapan secara farmasetik meliputi bentuk sediaan dan kekuatan sediaan. 
Aulia Nadya Rizki Imansari, Yuni Mutmainah, Frida Kasumawati

Gambaran Medication Error Tahap Peresepan di Apotek dan Klinik Keluarga

Tabel I. Kelengkapan Administratif dan Farmasetik secara keseluruhan

\begin{tabular}{cccc}
\hline No. & $\begin{array}{c}\text { Kelengkapan } \\
\text { Administratif dan } \\
\text { farmasetik }\end{array}$ & $\begin{array}{c}\text { Jumlah } \\
\text { (n) }\end{array}$ & $\begin{array}{c}\text { Persentase } \\
\text { (\%) }\end{array}$ \\
\hline 1 & Lengkap & 0 & 0 \\
2 & Tidak Lengkap & 270 & 100 \\
\hline
\end{tabular}

Berdasarkan Tabel 1, dapat diketahui hasil analisis ketidaklengkapan resep yang ditulis oleh dokter yaitu resep tidak lengkap secara keseluruhan sebanyak 100\% (270 lembar resep), dimana dikatakan tidak lengkap karena resep ada yang tidak mencantumkan nama pasien, umur pasien, jenis kelamin, berat badan, nama dokter, paraf dokter, No SIP dokter, tanggal penulisan resep, bentuk obat, serta kekuatan sediaan obat. Sehingga resep yang dikatakan lengkap yaitu $0 \%$ (0 lembar resep).

Tabel II. Kelengkapan Administratif

\begin{tabular}{cccccc}
\hline & \multirow{2}{*}{$\begin{array}{c}\text { Format } \\
\text { No }\end{array}$} & \multicolumn{2}{c}{ Lengkap } & \multicolumn{2}{c}{ Tidak Lengkap } \\
\cline { 3 - 6 } & $\begin{array}{c}\text { Kelengkapan } \\
\text { Administratif }\end{array}$ & $\begin{array}{c}\text { Jumlah } \\
\text { (n) }\end{array}$ & $\begin{array}{c}\text { Persentase } \\
\text { (\%) }\end{array}$ & $\begin{array}{c}\text { Jumlah } \\
\text { (n) }\end{array}$ & $\begin{array}{c}\text { Persentase } \\
\text { (\%) }\end{array}$ \\
\hline 1 & Nama Pasien & 266 & 99 & 4 & 1 \\
2 & Umur Pasien & 109 & 40 & 161 & 60 \\
3 & Jenis Kelamin & 35 & 13 & 235 & 87 \\
4 & Berat Badan & 0 & 0 & 270 & 100 \\
5 & Nama Dokter & 206 & 76 & 64 & 24 \\
6 & SIP Dokter & 115 & 43 & 155 & 57 \\
7 & Tanggal Resep & 197 & 73 & 73 & 27 \\
8 & Paraf Dokter & 46 & 17 & 224 & 83 \\
\hline
\end{tabular}

Berdasarkan pada Tabel 2, pada hasil penelitian yang terdapat ketidak lengkapan data berat badan memiliki persentase tertinggi pertama, dimana data berat badan merupakan aspek yang sangat penting dicantumkan karena digunakan dalam perhitungan dosis, apalagi untuk pasien anak sangat diperlukan data berat badan. Dalam penentuan dosis anak para ahli telah membuat rumus khusus berdasarkan berat badan seseorang ${ }^{8,9}$. Ketidaklengkapan dengan persentase tertinggi kedua yaitu pada data jenis kelamin. Tidak dicantumkannya data jenis kelamin ini dapat mempengaruhi terhadap pelayanan pengobatan, karena pasien bisa saja memiliki nama yang sama sehingga dapat dibedakan dengan melihat data jenis kelaminnya ${ }^{10,11}$. Pada data paraf dokter memiliki persentase 
tertinggi ketiga, dimana paraf dokter juga berperan penting dalam resep agar dapat menjamin keaslian resep dan berfungsi sebagai legalitas dan keabsahan resep tersebut $^{12,13}$.

Tabel III. Kelengkapan Farmasetik

\begin{tabular}{cccccc}
\hline \multirow{2}{*}{ No. } & \begin{tabular}{c} 
Format \\
Kelengkapan \\
\cline { 3 - 6 }
\end{tabular} & \multicolumn{2}{c}{ Lengkap } & \multicolumn{2}{c}{ Tidak Lengkap } \\
\cline { 3 - 6 } & Farmasetik & $\begin{array}{c}\text { Jumlah } \\
\text { (n) }\end{array}$ & $\begin{array}{c}\text { Persentase } \\
(\mathbf{\%})\end{array}$ & $\begin{array}{c}\text { Jumlah } \\
\text { (n) }\end{array}$ & $\begin{array}{c}\text { Persentase } \\
(\%)\end{array}$ \\
\hline 1 & Bentuk Sediaan & 194 & 72 & 76 & 28 \\
2 & Kekuatan Sediaan & 63 & 23 & 207 & 77 \\
\hline
\end{tabular}

Berdasarkan pada Tabel 3, diketahui hasil analisis kelengkapan resep secara farmasetik menunjukkan bahwa data ketidaklengkapan resep yang diperoleh mencakup data bentuk sediaan sebanyak $28 \%$, dan kekuatan sediaan sebanyak $77 \%$. Kekuatan sediaan merupakan aspek penting yang harus tercantum di dalam resep, karena kekuatan sediaan merupakan suatu penanda obat yang diresepkan oleh dokter dan juga diperlukan untuk mengecek apakah obat yang diresepkan oleh dokter sudah tepat dosis atau tidak untuk pasien tersebut, agar tidak terjadi medication error dalam pengobatan khususnyaa pada terapi yang diberikan ${ }^{14,15,16}$. Adanya bentuk sediaan juga sangat berpengaruh terhadap keberhasilan pengobatan pasien karena pemilihan bentuk sediaan merupakan kebutuhan, kondisi, dan keadaan yang diperlukan oleh tubuh ${ }^{17,18}$, contohnya seperti terdapat paracetamol yang memiliki lebih dari satu jenis bentuk sediaan. Maka dari itu penulisan bentuk sediaan obat seperti tablet atau syrup sangat penting ${ }^{19}$.

\section{KESIMPULAN DAN SARAN}

Berdasarkan hasil gambaran medication error tahap peresepan di Apotek dan Klinik Keluarga Sehat Muncul periode Januari - Desember Tahun 2020, dapat disimpulkan bahwa persentase kejadian medication error yang terjadi pada fase prescribing di Apotek dan Klinik Keluarga Sehat Muncul sebesar 100\%. Kelengkapan administratif meliputi nama pasien $1 \%$, umur pasien $60 \%$, jenis kelamin $87 \%$, berat badan $100 \%$, nama dokter $24 \%$, no SIP dokter 57\%, tanggal resep $27 \%$, paraf dokter $83 \%$, kelengkapan farmasetik meliputi bentuk obat $28 \%$, kekuatan sediaan $77 \%$. 
Aulia Nadya Rizki Imansari, Yuni Mutmainah, Frida Kasumawati Gambaran Medication Error Tahap Peresepan di Apotek dan Klinik Keluarga

Berdasarkan hasil penelitian yang telah dilakukan peneliti, maka saran yang dapat diberikan yaitu agar pada penelitian selanjutnya dilakukan analisis mengenai faktor-faktor yang mempengaruhi terjadinya prescribing error dan analisis potensi medication error dari segi transcribing (pembacaan resep), dan segi dispensing (peracikan obat). Menjadi referensi dan bahan bacaan untuk menambah wawasan khususnya mengenai medication error tahap Peresepan. Pelayanan peresepan diharapkan dapat menerapkan PERMENKES RI No. 73 tahun 2016 dengan memperhatikan komponen-komponen kelengkapan resep sehingga resiko kesalahan pada resep dapat dihindari.

\section{KONFLIK KEPENTINGAN}

Seluruh penulis menyatakan tidak terdapat potensi konflik kepentingan dengan penelitian dan atau publikasi artikel ini.

\section{DAFTAR PUSTAKA}

1. Khairurrijal MAW, Putriana NA. Review : Medication Erorr Pada Tahap Prescribing, Transcribing, Dispensing, dan Administration. Farmasetika.com (Online). 2018;2(4):8.

2. Saleem R, Dayo A, Ghoto MA. Medication Errors and Pharmacist Intervention at Government Hospital of Hyderabad, Pakistan. J Pharm Res Int. 2021;33(12):37-43.

3. Wahab A. Original Article Medication Errors Assessment and Prevention by a Clinical Pharmacist in Pediatric Wards of RMI Hospital Peshawar, KPK-Pakistan. Ann Pakistan Inst Med Sci. 2015;11(3):124-8.

4. Kumalasari I, Machmud R, Lestari Y, Velutina I. Pengaruh Implementasi Pelayanan Farmasi Klinis Terhadap Medication Error di RSUD Pariaman. Sci J Farm dan Kesehat. 2021;11(1):71-81.

5. Kang JS, Lee MH. Overview of therapeutic drug monitoring. Korean J Intern Med. 2009;24(1):1-10.

6. Kementrian Kesehatan RI. Standar Pelayanan Kefarmasian di Rumah Sakit [Internet]. Bulletin of the Seismological Society of America. Jakarta; 2016.

7. Noor J. Metodologi Penelitian. Jakarta: Kencana; 2012. 111-158 p.

8. Mamarimbing M, Fatimawali, Bodhi W. Evaluasi Kelengkapan Resep dari Dokter Spesialis Anak padaTiga Apotek di Kota Manado. J Pharmachon [Internet]. 2012; Vol 1(2):1-6.

9. Febrianti Y, Ardiningtyas B, Asadina E. Kajian Administratif, Farmasetis, dan Klinis Resep. J Pharmascience. 2018;05(02):163-72.

10. Megawati Fitria SP. Pengkajian Resep Secara Administratif berdasarkan Peraturan Menteri Kesehatan Ri No 35 Tahun 2014 pada Resep Dokter Spesialis Kandungan di Apotek Sthira Dhipa. J Ilm Medicam. 2017;3(1):12-6.

11. Lancaster K, Thabane L, Tarride JE, Agarwal G, Healey JS, Sandhu R, et al. Descriptive analysis of pharmacy services provided after community pharmacy

INPHARNMED Journal, Vol.5, No.2, Tahun 2021, 1-7 
screening. Int J Clin Pharm [Internet]. 2018;40(6):1577-86. Available from: https://doi.org/10.1007/s11096-018-0742-5

12. Bustami B, Fitri K. Persepsi Konsumen terhadap Pelayanan Kefarmasian Apotik di Jemadi Natural. J Dunia Farm. 2019;2(2):101-13.

13. Lestari DF, Fatimatuzzahra, Dominica D. Potensi Medication errorPada Resep di Salah Satu Apotek di Kota Kadipaten. J Sains dan Kesehat. 2020;3(4):242-7.

14. Toklu $\mathrm{HZ}$. The role of the doctor and pharmacist in improving patient compliance in the process of rational drug use. Turkiye Aile Hekim Derg. 2010;14(3):139-45.

15. Aziz A, Putra S, Jati SP. Peran Dokter Dalam Pencegahan Dan Penanggulangan Medication Error Di Rumah Sakit ( Studi di RSI NU Kabupaten Demak ). J Manaj Kesehat Indones. 2018;6(1):81-90.

16. Indiyani NNS, Lolo WA, Rundengan G. Physicians Perceptions Toward The Roles Of Pharmacisis in Pharmaceutical Care at Robert Wolter Mongisidi Hospital Manado. Pharmacon. 2020;9(3):357-64.

17. Agrawal A, Aronson JK, Britten N, Ferner RE, De Smet PA, Fialová D, et al. Medication errors: Problems and recommendations from a consensus meeting. $\mathrm{Br}$ J Clin Pharmacol. 2009;67(6):592-8.

18. Umar BU, Haque M. Prescribing skill and medication error: Role of pharmacology teaching. Int J Pharm Res. 2015;7(2):10-6.

19. Triswanto HW, Siti S, Riska J, Wardini A. Identification of Medication Error in Prescribing in Pharmaceutical Outpatient, Taman Husada Bontang Hospital Period, 1 March-16 April 2019. Malaysian J Med Res. 2019;03(04):8-12. 